\title{
A PESQUISA NO PROCESSO DE FORMAÇÃO DE PROFESSORES: ARTICULADOR E INTEGRADOR DE SABERES NECESSÁRIOS À PRÁTICA PEDAGÓGICA E DOCENTE ${ }^{1}$
}

\author{
Sílvio Ribeiro da Silva ${ }^{2}$ - Universidade Federal de Goiás/Campus Jataí - \\ shivonda 0 gmail.com \\ Karem Nacostielle Eufrásio ${ }^{3}$ - Universidade Federal de Goiás/Campus Jataí - \\ karemnacostielle@gmail.com
}

Resumo: Neste estudo, apresentamos, de maneira parcial, resultados de uma pesquisa que pretendeu identificar como está ocorrendo a produção científica nos nove (09) cursos de licenciatura (Física, Matemática, Química, Ciências Biológicas, Educação Física, Geografia, História, Pedagogia e Letras) do Campus Jataí (CAJ/UFG). Seus principais objetivos foram: (i) identificar concepções e intenções de docentes e alunos relacionadas ao ensino com pesquisa no processo de formação no curso de licenciatura e (ii) tomar conhecimento das pesquisas feitas pelos alunos dos nove (09) cursos de licenciatura do CAJ/UFG, identificando se são voltadas ou não para a educação básica do município de Jataí e da região. Para a análise e discussão dos dados, usamos o aprofundamento teórico de base interpretativista. Por estar vinculado à perspectiva interpretativista, o estudo ficou, também, enquadrado dentro da ótica proposta pelo paradigma indiciário de Ginzburg (1991). Os resultados indicaram que, dentre outras questões, falta maior participação dos docentes e alunos dos cursos de licenciatura em projetos PROLICEN. Outro aspecto diz respeito à urgente necessidade de mudança de postura de alguns docentes que consideram que a pesquisa não se aplica à formação de professores. Também o número de alunos envolvidos em atividades de pesquisa na unidade precisa ser ampliado. Para isso, a instituição poderia investir em políticas de divulgação de seus trabalhos de pesquisa junto à comunidade estudantil. Isso poderia despertar o interesse daqueles alunos que ainda não manifestaram esse tipo de interesse.

Palavras-chave: Pesquisa na universidade; Produção científica; Licenciatura; Formação de professores

Abstract: This work presents partial results of a study that intended to identify how the scientific production is occurring in the 09 undergraduate courses (Physics, Mathematics, Chemistry, Biological Sciences, Physical Education, Geography, History, Education, and Letters) at Campus Jataí (CAJ/UFG). Its main objectives were (i) to identify teachers and students' conceptions and intentions related to teaching with research in the educational process in the undergraduate course and (ii) to take notice of the research done by the students of the 09 undergraduate programs at $\mathrm{CAJ} / \mathrm{UFG}$, identifying whether or not they are directed to

\footnotetext{
${ }^{1}$ Estudo financiado pelo PROLICEN/UFG (Programa de Bolsas de Licenciatura).

${ }^{2}$ Mestre em Linguística. Doutor em Linguística Aplicada. Professor Adjunto I do curso de Letras do Campus Jataí da Universidade Federal de Goiás.

${ }^{3}$ Aluna do curso de Psicologia do Campus Jataí da Universidade Federal de Goiás. Bolsista PROLICEN.
} 
basic education in the city of Jataí and region. For the analysis and discussion of the data, we use an interpretive theoretical basis. Due to the fact that the study is bind to the interpretative perspective, it was also framed within the view offered by the paradigm of Ginzburg (1991). The results indicated that, among other issues, lacks a greater involvement of teachers and students of undergraduate courses in PROLICEN projects. Another aspect refers to the urgent need for change in attitude of some teachers who believe that research does not apply to teacher's formation. Also, the number of students involved in research activities at CAJ/UFG needs to be expanded. For this, the institution could invest in disclosure policies of its research works within the student community. This could arouse interest of those students who do not yet have expressed such an interest.

Keywords: University research; Scientific Production; Undergraduate Course, Teacher's formation

Neste artigo, apresentamos os resultados de um estudo que objetivou identificar concepções e intenções de docentes e alunos relacionados ao ensino com pesquisa no processo de formação no curso de licenciatura, bem como apresentar um levantamento quantitativo dos trabalhos de pesquisa científica feitos pelos alunos dos nove (09) cursos de licenciatura do $\mathrm{CAJ} / \mathrm{UFG}$ e tomar conhecimento das pesquisas feitas pelos alunos e docentes desses cursos, identificando se são voltadas ou não para a educação básica do município de Jataí e da região.

Levamos em conta, para sua realização, que a produção científica pode ser definida "como qualquer investigação metódica, desenvolvida para fornecer informações que possam solucionar um problema” (VICKERRY,1972, p. 33).

Geralmente, quando se pensa em pesquisa nos cursos de licenciatura, esta é articulada com a elaboração do trabalho de conclusão de curso (TCC/Monografia), sendo esses trabalhos, em geral, relatórios de estágio. É de suma importância a indissociabilidade da teoria e da prática ao longo do processo de formação dos alunos, estando este não somente relacionado com o TCC/Monografia. Fávero (1992) aponta-nos que uma pedagogia desarticulada faz com que os estudantes possam até saber sobre as teorias, no entanto, não vêem a utilidade destas em relação à sua prática.

A pesquisa deve estar presente no ambiente acadêmico, em especial nos cursos de licenciatura, por proporcionar aos futuros professores meios para que estes possam ter um olhar crítico constante em relação às suas práticas, problematizando-as e tendo instrumentos investigativos para modificá-las. Percebemos que a articulação entre teoria e prática na formação de professores é de fundamental importância, pois como aponta Cunha (2000, p. 47)

O professor, para construir sua profissionalidade, precisa recorrer a saberes da prática e da teoria. A prática vem sendo cada vez mais valorizada como espaço de construção de saberes, quer na formação dos professores, quer na aprendizagem dos alunos. Entretanto, a prática, que é fonte de sabedoria, torna a experiência um ponto de reflexão, sendo a teoria uma contribuição para a pesquisa e a reflexão. 
Vale ressaltar que o uso da pesquisa é obrigatório nos Institutos de Educação Superior (IES), em especial nas universidades. A política de formação de professores da UFG tem, dentre os seus princípios, o de promover a pesquisa como meio de produção de conhecimento e intervenção na prática social. Ou seja, os futuros professores devem elaborar meios que façam a diferença na sua prática de ensino para uma melhor qualificação dos respectivos alunos. A Resolução CEPEC $n^{\circ}$ 631, de 14 de outubro de 2003, define a política da universidade para a Formação de Professores da Educação Básica. Na alínea VI do $\S 1^{\circ}$ (Art. $1^{\circ}$ ) fala-se que, dentre os princípios dessa política, um deles é o de promover a pesquisa como meio de produção de conhecimento e intervenção na prática social (ênfase adicionada). Com base nesses princípios, um dos objetivos da UFG, segundo a resolução, é formar professores que tenham a pesquisa como uma dimensão da formação e do trabalho docente. Assim, fica claro que a pesquisa na UFG é parte integrante também dos cursos de licenciatura, cujo objetivo central é formar professores.

A Lei de Diretrizes e Bases da Educação Nacional (LDB/1996) estabelece que as instituições de ensino superior desenvolvam pesquisa, como pode ser visto no artigo reproduzido na sequência:

Art. 43 - A educação superior tem por finalidade:

(...)

III - incentivar o trabalho de pesquisa e investigação científica, visando o desenvolvimento da ciência e da tecnologia e da criação e difusão da cultura, e, desse modo, desenvolver o entendimento do homem e do meio em que vive .

(...)

No meio acadêmico, muito já foi discutido sobre a obrigatoriedade da pesquisa a ser desenvolvida pelas IES. Em relação às universidades não há qualquer dúvida quanto a isso, tendo em vista que a Constituição Federal estabelece expressamente:

Art. 207. As universidades gozam de autonomia didático-científica, administrativa e de gestão financeira e patrimonial, e obedecerão ao princípio de indissociabilidade entre ensino, pesquisa e extensão (ênfase adicionada).

Levando esses aspectos em conta, nosso estudo possibilitou traçar um panorama de que identidade profissional está sendo formada nos cursos de licenciatura do CAJ/UFG, numa tentativa de problematizar se essa identidade formada poderá ou não contribuir com o ensino. Preocupamo-nos em observar se a formação dada na licenciatura do CAJ/UFG está voltada diretamente para empreender um futuro profissional que cuidará da tarefa de ensinar aos alunos conteúdos e, além disso, alguém que terá sempre em mente a importância da observação de aspectos intrínsecos e extrínsecos à sua prática pedagógica, estando sempre pronto para executar uma pesquisa, buscando a melhoria da qualidade do seu ensino e da escola na qual ele trabalha. A esse respeito, Moraes (2004, p. 38) diz que "somente um professor pesquisador saberá orientar adequadamente seus alunos em suas investigações". 
Para Pavanello (2003), o professor deve ter a sua disposição um conhecimento abrangente, que faça com que ele não se limite a conteúdos e, sim, observe que é mais importante ter um conhecimento diferenciado desses conteúdos.

Além de ser real o fato de que grande parte dos alunos da licenciatura desconhece a importância da pesquisa na sua formação, é também real que grande parte dos professores da educação básica possui o mesmo desconhecimento em relação à sua prática cotidiana.

O estudo foi desenvolvido em cinco etapas. Na primeira etapa buscamos analisar os Projetos Pedagógicos de Curso (PPC) dos nove cursos de licenciatura, identificando a existência ou não de diretrizes didádico-pedagógicas que orientem os professores a desenvolver a pesquisa em sua prática de ensino, pensando em compreender como este processo ocorre na formação do aluno.

Na segunda etapa estava prevista uma entrevista informal ${ }^{4}$ (inicialmente pensada mediante a resposta a um pequeno questionário) com os alunos, aleatoriamente ${ }^{5}$, procurando saber quais docentes trabalham com pesquisa e qual pesquisa estava sendo realizada, segundo conhecimento dos alunos.

A terceira etapa consistiu em uma entrevista semi-estruturada ${ }^{6}$ com os docentes que mais foram citados pelos alunos. Na entrevista, buscamos saber como os docentes percebem a pesquisa no processo de formação de seus alunos, futuros professores, bem como quais suas condições funcionais na universidade, infra-estrutura do $\mathrm{CAJ} / \mathrm{UFG}$, recursos financeiros, dentre outros aspectos. Perguntamos, ainda, com quais alunos são realizadas as atividades de pesquisa, solicitando, também, melhores detalhes acerca desses trabalhos, como seus objetivos e, caso houvesse, qual a agência financiadora.

Na quarta etapa, entrevistamos os alunos envolvidos com pesquisa PIBIC/PIVIC ou PROLICEN, pedindo para que respondessem a um questionário. O objetivo deste questionário estava associado ao querer saber como esses alunos percebiam a pesquisa no processo de formação acadêmica, bem como quais os limites que eles vislumbravam para a prática da pesquisa no magistério, já que muitos deles atuarão como professores depois de concluído o curso. Vale ressaltar que só os alunos que se dispuseram a colaborar com o estudo responderam ao questionário.

A quinta e última etapa foi a de analisar e discutir os dados coletados pelos nove cursos de licenciatura do CAJ/UFG.

Na sequência, segue a apresentação dos dados de acordo com cada uma das etapas do estudo.

As questões feitas aos alunos foram : Qual é o seu curso? Quais os docentes que trabalham com pesquisa no seu curso? Como se dá esse trabalho? (PROLICEN, PROBEC, PIBIC, PIVIC, PROVEC, TCC-Monografia, outros)?

Os alunos envolvidos foram aqueles matriculados a partir do $2^{\circ}$ período, levando em conta que, possivelmente, já tinham interagido com parte do corpo docente, além de, talvez, terem vivido já algum tipo de experiência teórico-prática.

6 A entrevista semi-estruturada, segundo André (2000), é um dos tipos de coleta de dado mais rica, sendo estruturado por perguntas precisas. 


\section{Considerações sobre os projetos pedagógicos de curso (PPC)}

A partir do estudo dos PPC de cada um dos cursos, obtivemos relevantes informações acerca de como cada um desenvolve atividades de pesquisa com os alunos.

Depois de vislumbrados os PPC dos cursos de licenciatura do CAJ/UFG, partimos para o levantamento de algumas categorias que permitissem uma visualização de ordem geral, de acordo com os dados detectados nos documentos.

Elaboramos, então, as seguintes categorias para uma análise mais pontual:

1. O curso segue o PPC de Goiânia: a partir dessa constatação, podemos considerar que os cursos que não apresentam seus próprios PPC podem estar perdendo em relação aos que já possuem, uma vez que a realidade do alunado do Campus Jataí é, por razões óbvias, diferente da realidade dos alunos de Goiânia. Usar os mesmos parâmetros acadêmicos em ambas as cidades não trará resultados satisfatórios para Jataí, certamente.

2. O curso apresenta diretrizes que orientam a pesquisa: nesta categoria, observamos a apresentação dessas diretrizes, o que nos daria importantes informações acerca de como os cursos realizam as atividades de orientação das pesquisas desenvolvidas por cada um.

3. O curso orienta pesquisa apenas para realização do trabalho de conclusão de curso: com esta categoria, teríamos condições de observar quais cursos priorizavam o trabalho de conclusão de curso em detrimento de outras atividades de pesquisa. É bom lembrar que a pesquisa não deve se restringir apenas à realização do trabalho final do curso, mesmo porque certos trabalhos dessa natureza não apresentam necessidade de procedimentos que digam respeito à pesquisa, como coleta de dados, por exemplo.

4. O curso desenvolve pesquisa associada a órgãos de fomento: esta categoria foi criada pensando em fazer um levantamento de que órgãos de fomento financiam pesquisa no $\mathrm{CAJ} / \mathrm{UFG}$.

5. O curso propõe pesquisa ao longo do curso ou isolada: a função desta categoria foi a de observar, mais detidamente, em que ponto ao longo de cada um dos cursos a pesquisa é desenvolvida. O ideal é que seja continuamente, não somente em um momento específico, em geral no final do curso, como mencionado antes.

O que podemos visualizar a partir das categorias é o seguinte:

Tabela 1: Ocorrências vinculadas ao PPC

\begin{tabular}{|l|l|l|l|l|l|} 
Cursos & Categoria & Categoria & Categoria & Categoria & Categoria \\
\hline
\end{tabular}




\begin{tabular}{|c|c|c|c|c|c|}
\hline & $\mathbf{1}$ & $\mathbf{2}$ & $\mathbf{3}$ & $\mathbf{4}$ & $\mathbf{5}$ \\
\hline Matemática & $\mathbf{X}$ & $\mathbf{X}$ & & $\mathbf{X}$ & $\mathbf{X}$ \\
\hline Geografia & & $\mathbf{X}$ & & $\mathbf{X}$ & $\mathbf{X}$ \\
\hline História & $\mathbf{X}$ & $\mathbf{X}$ & & $\mathbf{X}$ & $\mathbf{X}$ \\
\hline $\begin{array}{c}\text { Ciências } \\
\text { biológicas }\end{array}$ & & $\mathbf{X}$ & & $\mathbf{X}$ & $\mathbf{X}$ \\
\hline Química & & $\mathbf{X}$ & & $\mathbf{X}$ & $\mathbf{X}$ \\
\hline Pedagogia & & $\mathbf{X}$ & & $\mathbf{X}$ & $\mathbf{X}$ \\
\hline Letras & $\mathbf{X}$ & $\mathbf{X}$ & & $\mathbf{X}$ & $\mathbf{X}$ \\
\hline Educação física & & $\mathbf{X}$ & & $\mathbf{X}$ & $\mathbf{X}$ \\
\hline Física & & $\mathbf{X}$ & & $\mathbf{X}$ & $\mathbf{X}$ \\
\hline $\begin{array}{c}\text { Equivalência } \\
\text { percentual }\end{array}$ & $\mathbf{3 3 \%}$ & $\mathbf{1 0 0 \%}$ & $\mathbf{0 \%}$ & $\mathbf{1 0 0 \%}$ & $\mathbf{1 0 0 \%}$ \\
\hline
\end{tabular}

Encerrada a primeira etapa do levantamento de dados, partimos para a seguinte, que foi a entrevista informal com os alunos.

\section{Considerações sobre entrevista informal com os alunos}

O principal objetivo desta fase da pesquisa foi detectar que tipo de conhecimento os alunos tinham acerca do trabalho de seus docentes e, de certa forma, de seu curso.

Em relação à primeira questão sobre qual curso faziam os alunos, os dados obtidos, em valores percentuais, foram os seguintes.

\section{Tabela 2: Que curso faziam os alunos}

\begin{tabular}{|c|c|}
\hline Curso & $\begin{array}{c}\text { Valor } \\
\text { percentual }\end{array}$ \\
\hline Letras & $16 \%$ \\
\hline Pedagogia & $16 \%$ \\
\hline História & $13 \%$ \\
\hline Geografia e Química e Ciências biológicas & $11 \%$ \\
\hline Matemática & $9 \%$ \\
\hline Física & $7 \%$ \\
\hline Educação física & $5 \%$ \\
\hline
\end{tabular}

A maioria dos alunos ser dos cursos de Letras e Pedagogia era um dado esperado. Primeiro porque Letras é um curso com duas habilitações (Inglês e Português) e isso, de certa forma, garante um número considerável de matriculados. Segundo, porque Pedagogia funciona em dois turnos (matutino e noturno), o que, também, dá a ele a oportunidade de possuir um bom número de matriculados.

O dado que chama atenção diz respeito ao número de alunos do curso de Educação Física, tendo em vista ser ele um dos mais antigos (iniciado nos anos 90). O número de alunos participantes desse curso ser pequeno chama atenção se comparado esse número 
com o equivalente ao curso de História, o qual ainda não formou nem a sua primeira turma, e apresentou uma quantidade de alunos interessados em participar da coleta de dados quase o dobro maior.

Os dados obtidos acerca da segunda questão feita aos alunos na entrevista informal foram os seguintes.

Tabela 3: Docentes que trabalham com pesquisa segundo os alunos

\begin{tabular}{|c|c|c|}
\hline \multicolumn{2}{|l|}{ Curso } & $\begin{array}{c}\text { Indicação dos } \\
\text { alunos }\end{array}$ \\
\hline \multirow[t]{4}{*}{ Docentes que trabalham com pesquisa } & Cátia & $20 \%$ \\
\hline & $\begin{array}{c}\text { Renata, } \\
\text { Paulo e } \\
\text { Keila }\end{array}$ & $16 \%^{8}$ \\
\hline & $\begin{array}{l}\text { Lílian e } \\
\text { Marinês }\end{array}$ & $8 \%$ \\
\hline & Outros $^{9}$ & $16 \%$ \\
\hline \multicolumn{3}{|c|}{ Física } \\
\hline \multirow[t]{3}{*}{ Docentes que trabalham com pesquisa } & $\begin{array}{c}\text { Alessandro, } \\
\text { Henrique e } \\
\text { Ismael }\end{array}$ & $24 \%{ }^{10}$ \\
\hline & Sauli & $20 \%$ \\
\hline & $\begin{array}{l}\text { Roosevelt e } \\
\text { Fábio }\end{array}$ & $3 \%{ }^{11}$ \\
\hline \multicolumn{3}{|c|}{ Geografia } \\
\hline \multirow[t]{5}{*}{ Docentes que trabalham com pesquisa } & Zilda & $19 \%$ \\
\hline & Scopel & $15 \%$ \\
\hline & Hildeu & $11 \%$ \\
\hline & $\begin{array}{c}\text { Fábio, } \\
\text { Dimas, } \\
\text { Francis, } \\
\text { Cabral }\end{array}$ & $7 \%{ }^{12}$ \\
\hline & Outros & $23 \%$ \\
\hline \multicolumn{3}{|c|}{ História } \\
\hline \multirow[t]{4}{*}{ Docentes que trabalham com pesquisa } & Renata & $22 \%$ \\
\hline & $\begin{array}{l}\text { Marcos e } \\
\text { Cláudia }\end{array}$ & $18 \%{ }^{13}$ \\
\hline & Márcio & $11 \%$ \\
\hline & $\begin{array}{c}\text { Murilo, } \\
\text { Ana, } \\
\text { Cleusa }\end{array}$ & $7 \%{ }^{14}$ \\
\hline
\end{tabular}

Cada docente.

Enquadramos na categoria “outros" os docentes cuja indicação não atingiu 1\%.

Cada docente.

Cada docente.

Cada docente.

Cada docente.

Cada docente. 


\begin{tabular}{|c|c|c|}
\hline & Outros & $7 \%$ \\
\hline \multicolumn{3}{|c|}{ Letras } \\
\hline \multirow[t]{7}{*}{ Docentes que trabalham com pesquisa } & Sílvio & $44 \%$ \\
\hline & Maria & $38 \%$ \\
\hline & Neuda & $33 \%$ \\
\hline & Eliana & $22 \%$ \\
\hline & Rosidelma & $18 \%$ \\
\hline & Tatiana & $11 \%$ \\
\hline & $\begin{array}{c}\text { Fernanda e } \\
\text { Vânia }\end{array}$ & $4 \%{ }^{15}$ \\
\hline \multicolumn{3}{|l|}{ Matemática } \\
\hline \multirow[t]{5}{*}{ Docentes que trabalham com pesquisa } & Marcos & $33 \%$ \\
\hline & Esdras & $19 \%$ \\
\hline & $\begin{array}{c}\text { Adriana e } \\
\text { Luciana }\end{array}$ & $14 \%{ }^{16}$ \\
\hline & Fernando & $9 \%$ \\
\hline & Outros & $9 \%$ \\
\hline \multicolumn{3}{|l|}{$\begin{array}{r}\text { Pedagogia } \\
\end{array}$} \\
\hline \multirow[t]{5}{*}{ Docentes que trabalham com pesquisa } & Camila & $22 \%$ \\
\hline & Márcia & $16 \%$ \\
\hline & $\begin{array}{c}\text { Sueli } \\
\text { Santos e } \\
\text { Marta }\end{array}$ & $9 \%$ \\
\hline & $\begin{array}{c}\text { Elizabeth e } \\
\text { Hercília }\end{array}$ & $6 \%{ }^{17}$ \\
\hline & $\begin{array}{l}\text { Ari, José } \\
\text { Sílvio, } \\
\text { Laís, } \\
\text { Fátima, } \\
\text { Aparecida, } \\
\text { Alípio, } \\
\text { Murilo }\end{array}$ & $3 \%{ }^{18}$ \\
\hline \multicolumn{3}{|l|}{$\begin{array}{rr} & \text { Biologia } \\
\end{array}$} \\
\hline \multirow[t]{7}{*}{ Docentes que trabalham com pesquisa } & Frederico & $20 \%$ \\
\hline & Fabiana & $14 \%$ \\
\hline & $\begin{array}{l}\text { Sandra, } \\
\text { Cristiano, } \\
\text { Elaine }\end{array}$ & $11 \%^{19}$ \\
\hline & Fabiano & $8 \%$ \\
\hline & $\begin{array}{l}\text { Luzia, } \\
\text { Cláudia }\end{array}$ & $5 \%$ \\
\hline & Cristine & $2 \%{ }^{20}$ \\
\hline & Edésio, & $2 \%{ }^{21}$ \\
\hline
\end{tabular}

Cada docente.

Cada docente.

Cada docente.

Cada docente.

Cada docente.

Cada docente. 


\begin{tabular}{|l|c|c|}
\hline \multicolumn{2}{|c|}{ Química } & $\begin{array}{c}\text { Alessandra, } \\
\text { Marlon }\end{array}$ \\
\hline Docentes que trabalham com pesquisa & $\begin{array}{c}\text { Francis e } \\
\text { Wesley }\end{array}$ & $27 \%{ }^{22}$ \\
\cline { 2 - 3 } & Giovanni & $22 \%$ \\
\cline { 2 - 3 } & Maria & $13 \%$ \\
& Helena & \\
\cline { 2 - 3 } & Paulo e & $4 \%$ \\
& Ricardo & \\
\hline
\end{tabular}

Para a terceira questão direcionada aos alunos na conversa informal, os dados foram.

Tabela 4: Tipo de pesquisa desenvolvida pelos docentes segundo os alunos

\begin{tabular}{|c|c|}
\hline Tipo de pesquisa proposta pelos docentes & $\begin{array}{c}\text { Valor } \\
\text { percentual }\end{array}$ \\
\hline PIBIC/PIVIC & $45 \%$ \\
\hline TCC/Monografia & $30 \%$ \\
\hline PROLICEN & $17 \%$ \\
\hline PIBID & $8 \%$ \\
\hline
\end{tabular}

Quando abordados para responder à terceira questão, percebíamos que muitos alunos titubeavam, indicando não ter certeza do tipo de pesquisa que seus docentes desenvolviam na universidade. Esse dado mostra-nos que falta uma política de maior divulgação à comunidade acadêmica do que é feito. Muitos alunos, especialmente os iniciantes, sequer sabem o que é uma pesquisa, quanto mais que tipo de atividade dessa natureza seus docentes fazem.

\section{Considerações sobre a entrevista com os docentes}

Como na conversa inicial percebemos que a maioria dos alunos não tinha certeza de quais docentes trabalhavam com pesquisa e o tipo de pesquisa feita por eles, resolvemos enviar e-mails aos coordenadores dos nove (09) cursos de licenciatura investigados, perguntando quais docentes faziam esse tipo de atividade. Infelizmente, nem todos os coordenadores nos responderam. Com isso, ficamos impossibilitados de saber exatamente a existência de pesquisa, e se é ou não voltada para a Educação Básica, nos cursos de História, Matemática, Química e Geografia. Fomos informados pelo coordenador do curso de Geografia que ele chegou a encaminhar para os docentes o questionário, mas não nos 
informou quais eram os docentes do curso que faziam pesquisa. Nenhum deles respondeu. Os demais coordenadores sequer deram retorno.

O tempo para a coleta dos dados referentes aos docentes foi longo, uma vez que demoraram a responder e somente $12(40 \%)$ dos 30 docentes de cinco cursos de licenciatura responderam.

Os dados obtidos com esse questionário foram.

Tabela 5: Dados referentes ao questionário respondido pelos docentes

\begin{tabular}{|c|c|c|}
\hline Questões feitas & \multicolumn{2}{|c|}{ Valores percentuais } \\
\hline \multirow{5}{*}{ Curso em que atua } & Ciências Biológicas & $26 \%$ \\
\hline & Pedagogia & $20 \%$ \\
\hline & Letras & $13 \%$ \\
\hline & Educação Física & $13 \%$ \\
\hline & Física & $6 \%$ \\
\hline \multirow[t]{2}{*}{ Titularidade Máxima } & Doutor & $50 \%$ \\
\hline & Mestre & $50 \%$ \\
\hline Regime de trabalho & Dedicação Exclusiva & $100 \%$ \\
\hline \multirow[t]{5}{*}{ Tipo de pesquisa que está desenvolvendo } & PIBIC/PIVIC & $50 \%$ \\
\hline & PROLICEN & $31 \%$ \\
\hline & PIBID & $0 \%$ \\
\hline & TCC & $0 \%$ \\
\hline & Outros & $18 \%$ \\
\hline \multirow[t]{3}{*}{$\begin{array}{l}\text { Como concebe o exercício da pesquisa na formação de } \\
\text { professores }\end{array}$} & $\begin{array}{l}\text { Fundamental para a } \\
\text { formação de } \\
\text { professores }\end{array}$ & $63 \%$ \\
\hline & $\begin{array}{l}\text { Permite estabelecer } \\
\text { uma relação entre a } \\
\text { teoria e a prática } \\
\text { profissional }\end{array}$ & $27 \%$ \\
\hline & $\begin{array}{l}\text { Não se aplica à } \\
\text { formação de } \\
\text { professores }\end{array}$ & $9 \%$ \\
\hline \multirow[t]{4}{*}{ Quantidades de alunos que estão sendo orientados } & 1 a 10 & $63 \%$ \\
\hline & 10 em diante & $18 \%$ \\
\hline & Nenhum & $18 \%$ \\
\hline & Disciplina & $9 \%$ \\
\hline \multirow[t]{3}{*}{ Procura de alunos para concorrer a bolsa } & Pequena & $63 \%$ \\
\hline & Média & $27 \%$ \\
\hline & Grande & $9 \%$ \\
\hline \multirow[t]{4}{*}{ Agências que financiam pesquisa } & UFG & $53 \%$ \\
\hline & $\mathrm{CNPq}$ & $33 \%$ \\
\hline & FAPEG & $6 \%$ \\
\hline & Outras & $6 \%$ \\
\hline \multirow[t]{2}{*}{ Objetivos da atual pesquisa são } & $\begin{array}{l}\text { Voltados } \\
\text { diretamente para a } \\
\text { Educação Básica }\end{array}$ & $42 \%$ \\
\hline & Não voltados para a & $42 \%$ \\
\hline
\end{tabular}




\begin{tabular}{|c|c|c|}
\hline & Educação Básica & \\
\hline & $\begin{array}{l}\text { Voltados } \\
\text { indiretamente para a } \\
\text { Educação Básica }\end{array}$ & $14 \%$ \\
\hline \multirow[t]{3}{*}{ Limitações encontradas no desenvolvimento da pesquisa } & Financiamento & $45 \%$ \\
\hline & $\begin{array}{l}\text { Recursos materiais e } \\
\text { estruturais }\end{array}$ & $45 \%$ \\
\hline & $\begin{array}{l}\text { Alunos interessados } \\
\text { em pesquisa }\end{array}$ & $9 \%$ \\
\hline \multirow[t]{3}{*}{ Como as limitações atrapalham no desenvolvimento da pesquisa } & $\begin{array}{l}\text { Falta de recursos } \\
\text { materiais e } \\
\text { financeiros }\end{array}$ & $60 \%$ \\
\hline & Outros & $30 \%$ \\
\hline & Tempo & $10 \%$ \\
\hline \multirow[t]{3}{*}{$\begin{array}{l}\text { Se há limitações, o que pode ser feito par amenizar os pontos } \\
\text { negativos }\end{array}$} & $\begin{array}{l}\text { Maior investimento } \\
\text { de verbas para } \\
\text { pesquisa e infra- } \\
\text { estrutura }\end{array}$ & $70 \%$ \\
\hline & $\begin{array}{l}\text { Qualificação de } \\
\text { professores }\end{array}$ & $20 \%$ \\
\hline & $\begin{array}{l}\text { Incentivar os alunos } \\
\text { a fazerem pesquisa }\end{array}$ & $10 \%$ \\
\hline \multirow[t]{3}{*}{ Em que turmas é trabalhada a pesquisa } & $\begin{array}{l}\text { Quarto período em } \\
\text { diante }\end{array}$ & $54 \%$ \\
\hline & Nenhuma & $27 \%$ \\
\hline & $\begin{array}{l}\text { Em todas as } \\
\text { Disciplinas }\end{array}$ & $18 \%$ \\
\hline
\end{tabular}

O pequeno percentual de docentes do curso de Física condiz bem com a realidade do curso no campus. Trata-se de um curso novo (ainda não formou nenhuma turma) e com um número de docentes pequeno. $\mathrm{O}$ que chama a atenção é o pequeno número de retorno que obtivemos dos cursos de Letras (13\%) e Pedagogia $(20 \%)^{24}$.

Um dado positivo, e que vale a pena ressaltar, diz respeito à titularidade dos docentes. Nenhum dos que respondeu nosso questionário é apenas especialista, ou apenas graduado. No entanto, numa unidade que pretende se destacar como pólo de desenvolvimento de pesquisa, o ideal seria que o número de doutores fosse superior (com larga diferença, preferencialmente) ao número de mestres, especialmente por conta do tempo de existência do campus na cidade ${ }^{25}$. Outro ponto positivo está relacionado à carga horária de trabalho de todos os que responderam: dedicação exclusiva. Poder se dedicar exclusivamente às atividades universitárias pode favorecer o exercício da pesquisa por parte dos docentes. Para Ruzza (1990), “existem outros fatores que prejudicam a pesquisa científica, que estão

24 Não custa lembrar que pouco antes falamos que os dois cursos apresentam uma estrutura humana relativamente grande, uma vez que um tem duas habilitações (Letras) e o outro funciona em dois turnos (Pedagogia).

25 A unidade está prestes a completar 30 anos de fundação. 
relacionados com a não dedicação integral do pesquisador ao seu trabalho, pois a pesquisa é apenas um dos serviços que ele executa".

Em relação à questão que perguntou o tipo de pesquisa desenvolvida, temos mais um indício de que os alunos são desinformados a respeito do que é desenvolvido em seu curso. Quando perguntados sobre os tipos de pesquisa desenvolvidos pelos seus docentes na entrevista informal, 30\% responderam que era TCC/Monografia. Porém, $0 \%$ dos docentes assinalou esta opção ${ }^{26}$. O mesmo ocorreu em relação aos dados sobre pesquisa PIBID. Segundo os alunos, $8 \%$ de seus docentes desenvolvem pesquisa dessa natureza. No entanto, nenhum dos docentes assinalou esta opção de trabalho em sua prática acadêmica de pesquisador. A respeito da pesquisa PIBIC, é interessante observar a proximidade entre o que disseram os alunos (45\%) e o que disseram os docentes $(50 \%)$, não ocorrendo o mesmo em relação ao PROLICEN.

Consideramos positivo $50 \%$ dos docentes participantes deste estudo desenvolverem pesquisa PIBIC. Isso por conta da política da universidade de desenvolver pesquisas dessa natureza, visando, dentre outros objetivos, a despertar a vocação e desenvolver o pensamento científico mediante a participação de estudantes de graduação em projetos de pesquisa. Outra questão positiva, a nosso ver, é a participação de $31 \%$ dos docentes participantes desenvolverem ações vinculadas ao PROLICEN. O motivo de nosso contentamento é o fato de o PROLICEN visar à valorização das licenciaturas e a interação da universidade com a rede pública de ensino. Pelo fato de nosso estudo objetivar detectar se a pesquisa desenvolvida no CAJ é voltada à Educação Básica, ficaríamos mais satisfeitos se a maioria dos docentes desenvolvesse ações nessa perspectiva, tendo em vista que os cursos nos quais atuam são de licenciatura e as atividades deveriam focar aspectos voltados à futura docência dos alunos graduandos.

Causou-nos preocupação o fato de $9 \%$ dos docentes participantes afirmarem que a pesquisa não se aplica à formação de professores. Como um formador de docentes, atuante num curso de licenciatura, apresenta esse tipo de pensamento? A esse respeito, Schön (2004) diz que a pesquisa ocupa um lugar político social dentro de qualquer instituição, sobretudo nas educativas. Para o grupo de docentes que tem a ideia apresentada aqui, o pensamento de Schön não faz sentido.

Felizmente, um número considerável dos docentes participantes $(63 \%)$ concebe a pesquisa como fundamental para a formação de professores. Para eles, o exercício da pesquisa deve ser uma constante, um pólo desencadeador de aprendizagem (ROZA, 2005).

Outro ponto preocupante, a nosso ver, é o fato de $18 \%$ dos docentes participantes não ter nenhum orientando vinculado à pesquisa. Pode ser que esses docentes sem orientandos sejam os mesmos que afirmaram não ser a pesquisa aplicada à formação de professores.

A respeito da questão feita sobre a procura dos alunos pelas bolsas no momento de seleção, consideramos que o número mencionado pelos docentes (9\%) para a grande

\footnotetext{
26 Convém mencionar que, talvez, ocorreu de os $30 \%$ de docentes que desenvolvem pesquisa de
} TCC/Monografia citados pelos alunos terem sido os que não devolveram o questionário respondido. 
procura é extremamente baixo. Afirmamos isso levando em conta que estão em observação 05 cursos, alguns deles com possibilidade de possuir um considerável número de alunos (Letras e Pedagogia, especificamente). Esse dado indica-nos que os alunos ainda estão desatualizados acerca da importância da pesquisa em sua formação acadêmica. Isso mostra o quanto seria importante a unidade investir em divulgação e motivação quanto à importância do exercício da pesquisa na formação do aluno futuro professor ${ }^{27}$.

$\mathrm{O}$ dado acerca das agências financiadoras das pesquisas chama a atenção. 50\% dos docentes participantes desenvolvem pesquisa PIBIC e 31\% pesquisa PROLICEN. Mesmo assim, informaram (53\%) que suas pesquisas são financiadas pela universidade (nesse dado está inserido o PROLICEN, por se tratar de um projeto da própria instituição). Se a maioria informou anteriormente que desenvolve pesquisa PIBIC, financiada pelo $\mathrm{CNPq}$, por que apenas 33\% disseram que suas pesquisas são financiadas por aquela agência de fomento? Aparentemente, um dado conflituoso.

Nossa expectativa quanto à questão sobre os objetivos da pesquisa atual desenvolvida pelos docentes era grande, tendo em vista que se questionava explicitamente se essa pesquisa é ou não voltada para a educação básica e isso está diretamente vinculado a um dos objetivos deste estudo. Teríamos ficado mais satisfeitos se o resultado dos dados mostrasse que a maioria das pesquisas atuais estão diretamente ligadas à educação básica. No entanto, apenas $42 \%$ dessas pesquisas vão diretamente a esse ponto, segundo os docentes participantes. É um dado que vai bem ao encontro da quantidade percentual de docentes que informou desenvolver pesquisa PROLICEN (31\%).

Outro dado do questionário que nos causava expectativa quanto ao resultado era ligado às limitações, percebidas pelos docentes, para o desenvolvimento de suas pesquisas. Esperávamos que a maioria assinalasse que a maior limitação seria ligada a recursos materiais e estruturais. No entanto, houve empate quanto ao número de docentes participantes que acha ser a maior limitação relacionada a isso e a quantidade deles que acha a maior limitação estar vinculada a financiamento. Esperávamos que a maioria dissesse ser recursos materiais e estruturais o maior empecilho por conta do que percebemos no campus relacionado a isso. É de conhecimento público que enfrentamos graves problemas estruturais, como falta de equipamento, falta de salas para docentes atenderem alunos e desenvolverem estudos e pesquisas, falta de laboratórios, dentre outros fatores. Grande parte dos docentes acharem que isso não é um empecilho para suas atividades acadêmico-docentes é um ponto positivo, por demonstrar que o grupo consegue se desvencilhar das dificuldades que surgem nesse aspecto.

Foi baixo o número percentual referente a dificuldades e limitações vinculadas à falta de interesse dos alunos pela pesquisa. Dado positivo, pois demonstra que, apesar de a procura dos alunos por bolsa de pesquisa ser pequena $(63 \%$ dos docentes participantes

27 O fato de os cursos de licenciatura funcionarem no período noturno pode ser um dos motivadores de baixa procura por parte dos alunos, vez que a maioria trabalha durante o dia e grande parte é responsável pelo próprio sustento e de sua família. Tendo em vista que o valor das bolsas é baixo, para muitos seria impossível o sustento apenas com ela. 
afirmaram isso), trata-se de um fato que não atrapalha a atividade de pesquisa do grupo de docentes participante.

Se $45 \%$ dos docentes afirma que recursos materiais são uma limitação para o desenvolvimento de suas pesquisas, 60\% colocam que a falta desses recursos é o que atrapalha seu trabalho. Achamos um pouco incompatíveis esses dados. Pela lógica, falta de recursos materiais deveria ter apresentado o mesmo número de escolha. Acabamos ficando sem saber o que os docentes entenderam como sendo recursos materiais.

Já em relação à opinião dos docentes sobre o que pode ser feito para amenizar os problemas causadores de empecilhos às suas atividades, os dados apontam sincronia entre o que fora dito antes. Afirmamos isso levando em conta que $70 \%$ dos participantes consideram que o investimento em verbas para pesquisa e infra-estrutura é o que deveria ser feito para diminuir os empecilhos encontrados e $60 \%$ consideram a falta de recursos materiais (incluídos aí aspectos ligados à infra-estrutura) o principal problema.

A respeito da questão que indagava em quais turmas era trabalhada pesquisa, causou-nos espanto $27 \%$ dos docentes afirmarem que em nenhuma turma fazia isso. É um dado considerável, tendo em vista que se refere a $1 / 3$ do total dos dados. Pensar que esse montante de turmas não realiza nenhum tipo de pesquisa é um pouco assustador se levarmos em conta se tratar de uma universidade e ser este um espaço onde a pesquisa é obrigação de todos. Pode ser que essas turmas sejam de responsabilidade dos $9 \%$ de docentes que não consideram a pesquisa como integrante da formação de professores.

\section{Considerações sobre a entrevista com os alunos}

$\mathrm{Na} 4^{\text {a }}$ etapa, momento em que estava prevista entrevista (feita com o uso de um questionário) com os alunos que desenvolvem pesquisa, foi preciso buscar informações na Assessoria de Pesquisa do campus. Através dessa assessoria obtivemos o endereço de e-mail de todos os alunos bolsistas PIBIC/PIVIC e PROLICEN. Então, enviamos o questionário a esses alunos.

Apenas 11 alunos bolsistas responderam o e-mail (12\% do total de alunos vinculados à pesquisa no CAJ). Esse número é irrisório, tendo em vista que em 2009/2010 havia 79 alunos PIBIC/PIVIC e 10 PROLICEN.

Desses 11 que responderam, 64\% foram entrevistados pessoalmente. Vale ressaltar que o tempo de duração da entrevista era de, em média, 10 minutos. Para os alunos que responderam ao questionário via e-mail (36\%), não temos como prever o tempo destinado a esse fim.

Os resultados obtidos foram.

Tabela 6: Dados referentes ao questionário respondido pelos alunos

\begin{tabular}{|l|l|l|}
\hline \multicolumn{2}{|c|}{ Questões feitas } & \multicolumn{2}{c|}{ Valores percentuais } \\
\hline \multirow{2}{*}{ Qual seu curso } & Ciências Biológicas & $36 \%$ \\
\cline { 2 - 3 } & Psicologia & $27 \%$ \\
\cline { 2 - 3 } & Letras & $18 \%$ \\
\hline
\end{tabular}




\begin{tabular}{|c|c|c|}
\hline & Educação Física & $9 \%$ \\
\hline & História & $9 \%$ \\
\hline \multirow[t]{3}{*}{ Pesquisa em que está vinculado } & PIBIC/PIVIC & $75 \%$ \\
\hline & PROLICEN & $25 \%$ \\
\hline & Outros & $00 \%$ \\
\hline $\begin{array}{l}\text { Qual é a importância da pesquisa na sua formação como } \\
\text { futuro professor }\end{array}$ & $\begin{array}{l}\text { Maior conhecimento de áreas } \\
\text { e de conteúdos }\end{array}$ & $72 \%$ \\
\hline
\end{tabular}




\begin{tabular}{|c|c|c|}
\hline & $\begin{array}{l}\text { Faz entrar em contato com a } \\
\text { prática }\end{array}$ & $18 \%$ \\
\hline & Outros & $9 \%$ \\
\hline Limitações da pesquisa em que está vinculado & $\begin{array}{l}\text { Faltam recursos financeiros de } \\
\text { materiais }\end{array}$ & $50 \%$ \\
\hline & $\begin{array}{l}\text { Tempo para a execução da } \\
\text { pesquisa }\end{array}$ & $30 \%$ \\
\hline & $\begin{array}{l}\text { Falta de compreensão das } \\
\text { pessoas sobre a importância } \\
\text { da pesquisa na universidade }\end{array}$ & $20 \%$ \\
\hline Como as limitações atrapalham no desenvolvimento da & Escassez de verba & $40 \%$ \\
\hline pesquisa & Outros & $30 \%$ \\
\hline & $\begin{array}{l}\text { Entendimento (ou falta dele) } \\
\text { das outras pessoas na própria } \\
\text { universidade sobre a } \\
\text { importância da pesquisa }\end{array}$ & $20 \%$ \\
\hline & Escassez de materiais & $10 \%$ \\
\hline $\begin{array}{l}\text { O que poderia ser feito para amenizar os pontos negativos } \\
\text { no desenvolvimento da pesquisa }\end{array}$ & $\begin{array}{l}\text { Maior incentivo dos docentes } \\
\text { para a pesquisa }\end{array}$ & $30 \%$ \\
\hline & Outros & $30 \%$ \\
\hline & Apoio da universidade & $20 \%$ \\
\hline & Verba & $20 \%$ \\
\hline
\end{tabular}

Diferente dos dados obtidos via entrevista informal, no questionário aplicado aos alunos, a maioria deles (36\%) era do curso de Ciências Biológicas. Na entrevista informal, a maioria dos alunos que se dispôs a colaborar era dos cursos de Letras e Pedagogia (16\% de cada). Comparando os dados dos alunos com os dos docentes, percebemos equivalência, levando em conta que a maioria dos docentes participantes $(26 \%)$ era também de Ciências Biológicas.

Outra equivalência percebida foi em relação à pesquisa a qual a maioria estava vinculada. $75 \%$ dos participantes disseram estar associado à pesquisa PIBIC, da mesma forma que a maioria dos docentes disse estar também vinculada a uma atividade dessa natureza. Em relação à participação em pesquisa PROLICEN, os alunos assinalaram esta opção como a segunda, da mesma forma que os docentes. Com isso, percebemos a existência de 'sintonia' entre o informe dos alunos e dos docentes, o que dá indício de fidedignidade entre as respostas de um e de outro grupo. Da mesma forma que em relação aos dados dos docentes, aqui, em relação aos dos alunos, preferíamos que maioria estivesse vinculada à pesquisa PROLICEN, por ela associar a universidade e a educação básica, esfera de atuação para onde irão os futuros professores formados pela licenciatura.

Ponto positivo percebido nesses dados, embora o número de alunos que escolheram essa opção tenha sido pequeno, diz respeito aos $18 \%$ deles que disseram que a 
pesquisa faz entrar em contato com a prática ${ }^{28}$. Em relação a isso, Tardif (2000) considera que o que é chamado de 'conhecimento' existe apenas através de um sistema de práticas. Com a fala do autor, podemos perceber o quanto a prática é importante para colocar em uso o que se entende como conhecimento.

Felizmente, a maioria dos alunos (72\%) percebe que a pesquisa proporciona um maior conhecimento da área de atuação e de conteúdos vinculados a essa área.

Outra questão que demonstrou sintonia entre docentes e alunos foi a que abordou o que limita o desenvolvimento da pesquisa na unidade. 50\% dos alunos assinalaram a opção "falta de recursos materiais", ao passo que essa opção foi a escolhida por $45 \%$ dos docentes participantes. Outra opção escolhida pelos alunos e que nos deu a indicação de que apresentam preocupação com o desenvolvimento de pesquisas na universidade foi "falta de compreensão das pessoas sobre a importância da pesquisa na universidade", assinalada por $20 \%$ dos alunos, como sendo uma das limitações da pesquisa na qual estavam vinculados na época da coleta dos dados. Essa opção vai ao encontro do que disseram os docentes, vez que a procura dos alunos por bolsa é pequena para $63 \%$ dos docentes. Assim, notamos que para ambos os grupos existe, de fato, baixo interesse dos alunos pelas bolsas de pesquisa, e para um conjunto de alunos isso é um empecilho para o desenvolvimento do trabalho. Fica faltando maior empenho da universidade na atividade de conscientizar os alunos da importância de ser pesquisador.

A mesma quantidade de alunos que assinalou que a falta de compreensão das pessoas sobre a importância da pesquisa na universidade é um empecilho para o desenvolvimento da atividade feita na época assinalou que o entendimento (ou falta dele) das pessoas na universidade sobre a importância da pesquisa atrapalha o desenvolvimento desse trabalho: $20 \%$. Esse dado nos indica bastante coerência no pensamento dos alunos quanto aos aspectos envolvidos com a pesquisa na instituição. Certamente, os mesmos alunos que acham que a falta de compreensão das pessoas sobre a importância da pesquisa na universidade limita a pesquisa feita naquele momento pensa que o entendimento das pessoas da própria universidade sobre a pesquisa atrapalha o desenvolvimento dessa atividade. Esse dado tende a nos remeter a outro, apresentado pelos docentes participantes. Quando 9\% disseram que a procura por bolsas no momento da seleção é pequena, notamos que, possivelmente, essa baixa procura se deve ao fato de que os alunos não têm um entendimento adequado acerca da importância da pesquisa na universidade e na sua formação acadêmica. A respeito desse dado dos alunos sobre o entendimento de pessoas da própria universidade sobre a importância da pesquisa, podemos entender que, certamente, entra nesse grupo discriminado pelos alunos os $9 \%$ de docentes que pensam que a pesquisa não se aplica à formação de professores. Aqueles que apresentam esse tipo de ideia podem acabar atrapalhando o desenvolvimento da atividade

28 A preocupação com a prática é importante. O ideal seria que os cursos de formação levassem em conta o que sugere Demo (1999), quando diz que, em se tratando de carga horária, deve-se destinar o mesmo tempo à teoria e à prática. 
na instituição, vez que deixam de contribuir com o avanço científico de seu curso, de seu grupo de trabalho, de seus alunos, o que é, a nosso ver, lamentável.

$\mathrm{O}$ dado sobre o que pode ser feito para diminuir as limitações relacionadas ao desenvolvimento de pesquisas pareceu-nos bastante interessante. $30 \%$ dos alunos pensam que cabe aos docentes oferecer maior incentivo para o desenvolvimento de atividades dessa natureza. Para $10 \%$ dos docentes, pode haver diminuição de limitações se houver maior incentivo aos alunos para que se interessem pela pesquisa. Pelo fato de os alunos apresentarem menos maturidade acadêmica, é plausível que um bom número deles pense que cabe aos docentes o maior incentivo para a pesquisa. Concordamos com esse montante de alunos, mesmo porque os docentes é quem têm mais experiência e conhecimento da importância da pesquisa na construção profissional de um aluno de nível superior, cabendo a ele, então, a tarefa de despertar nos alunos o interesse pela atividade. Pena que apenas $10 \%$ dos docentes apresentaram pensamento semelhante em relação aos alunos. Sendo a parte mais experiente, acreditamos que um número maior de integrantes desse grupo poderia ter demonstrado interesse em incentivar mais os alunos para participem de atividades de pesquisa.

\section{Conclusões/comentários finais}

A realização deste estudo trouxe-nos alguns desafios. O principal deles foi a falta de receptividade tanto dos docentes quanto dos alunos. Em relação aos docentes, dos 09 (nove) cursos de licenciatura existentes no CAJ/UFG, apenas em 05 (cinco) cursos houve colaboração. Dos docentes desses cursos, apenas 30\% participaram de fato, enviando o questionário de volta preenchido. Em relação aos alunos, apenas $12 \%$ dos que participavam efetivamente de atividades de pesquisa no $\mathrm{CAJ} / \mathrm{UFG}$ responderam ao questionário da entrevista. O motivo dessa 'resistência' de ambas as partes não sabemos. Pode ser por falta de tempo. Mas pode ser também por receio de trazer à tona ideias, ou ideais, que seriam pouco positivos em relação ao tema; pode ser por receio de divulgar que as pesquisas desenvolvidas não apresentam objetivos realmente contundentes; pode ser por receio de mostrar baixa produtividade.

Pelos resultados obtidos a partir das respostas aos questionários, percebemos que falta maior participação dos docentes dos cursos de licenciatura em projetos PROLICEN, pelo fato de que eles relacionam a universidade com a escola pública. Outro aspecto que achamos por bem comentar aqui diz respeito à urgente necessidade de mudança de postura de alguns docentes que consideram que a pesquisa não se aplica à formação de professores. Também o número de alunos envolvidos em atividades de pesquisa na unidade precisa ser ampliado. Para isso, como já mencionado, a instituição poderia investir em políticas de divulgação de seus trabalhos de pesquisa junto à comunidade estudantil. Isso poderia despertar o interesse daqueles alunos que ainda não perceberam a importância disso em sua formação.

Por se tratar de cursos de formação de professores, o número de pesquisas desenvolvidas pelos docentes poderia ser ampliado quando estas se dirigem a questões que visem à melhoria da educação básica. Pensamos que é também responsabilidade da 
universidade, além de formar bons profissionais, desenvolver métodos e técnicas que busquem melhorar o quadro do que já existe (o quadro educacional, para sermos mais precisos).

Em se tratando de políticas administrativas, seria interessante que as instâncias superiores da unidade investissem em melhorias estruturais e materiais. Para que o profissional universitário consiga desenvolver suas atividades de pesquisa eficientemente, é imprescindível a existência de ambiente de trabalho favorável. Essa questão acaba sendo um ponto negativo para o $\mathrm{CAJ} / \mathrm{UFG}$, vez que as condições materiais e estruturais são caóticas, mesmo sendo a unidade bastante antiga (prestes a completar 30 anos). Apesar disso, cabe mencionar que o corpo docente da unidade, em geral, atua de forma presente no desenvolvimento de pesquisas ${ }^{29}$.

Gostaríamos de dizer que a pesquisa deve ser encarada como algo inerente ao processo de formação educacional, sendo visualizada como o principal instrumento de aprendizagem no ensino superior. Nas palavras de Lampert (1999, p. 122), “a investigação deve ocorrer no âmbito da disciplina (desenvolvida nos cursos de formação) e da própria atividade docente para ter condições de transformar os processos de ensino e aprendizagem e produzir inovações e melhorias".

Para isso, faz-se urgente uma mudança de postura, investindo em disciplinas que sejam responsáveis pela 'formação' do pesquisador, sendo colocadas no início do curso de formação e ocupando boa parte do seu espaço, investindo na questão do 'como fazer pesquisa', buscando desenvolver as competências e habilidades necessárias a esse saber fazer.

Os alunos, futuros professores, que não tiverem a pesquisa como uma prática constante em sua formação fatalmente encontrarão dificuldades em sua atuação como profissionais em sala de aula. Dizemos isso em relação aos desafios que serão encontrados cotidianamente com os alunos e que exigirão postura dinâmica para sua solução. Essa postura diz respeito a saber, por exemplo, fazer levantamento das principais dificuldades dos alunos (levantamento de 'corpus'), análise de possíveis estratégias a serem usadas para resolução dessas dificuldades (estudo teórico) e aplicação dessas estratégias junto aos sujeitos, visando à solução de suas dificuldades de modo que, no final do processo, seja possível uma avaliação dos resultados (análise e conclusões).

É na universidade que a pesquisa encontra, por meio da inter-relação entre ensino e extensão, o ambiente favorável para seu desenvolvimento. À pesquisa está associada a produção do conhecimento científico, sendo que ela precisa seguir princípios metodológicos que darão validade assegurada a seus resultados. Esses resultados originam produtos materiais, tecnológicos, bem como textos, que costumam ser a principal maneira do cientista/pesquisador comunicar seus resultados com outros cientistas e demais pessoas da comunidade.

29 De julho de 2009 a julho de 2010 havia 43 (quarenta e três) pesquisas PIBIC/PIVIC em desenvolvimento e $10(\mathrm{dez})$ pesquisas PROLICEN. 
Pensamos que a ideia de realização deste estudo poderia ser levada aos outros campi da universidade, sendo desenvolvida por outros grupos de pesquisadores, no intuito de perceber como a pesquisa é vista nos cursos de licenciatura dessas unidades. No final, cruzando os dados de todos os campi seria possível vislumbrar, de maneira mais segura, como a Universidade Federal de Goiás, em seu todo, encara a pesquisa nos cursos de licenciatura e se essa pesquisa busca à melhoria da qualidade do ensino oferecido pela educação básica.

Referências bibliográficas

ANDRÉ, M. E. D. A. de. Etnografia da prática escolar. Campinas/SP: Papirus, 2000.

BRASIL. Constituição da República Federativa do Brasil. Brasília/DF: Senado, 1988.

BRASIL. Lei n 9.394, de 20 de dezembro de 1996. Diário Oficial da União. Brasília/ DF, 1996.

CUNHA, M. I. da. Ensino como mediação da formação do professor universitário. In: MOROSINI, M. [org.]. Professor do ensino superior: identidade, docência e formação. Brasília: Instituto Nacional de Estudos e Pesquisas Educacionais, 2000. p. 79-92.

DEMO, P. Pesquisa: princípio científico e educativo. São Paulo: Cortez, 1999.

FÁVERO, M. de L. de A. Universidade e estágio curricular: subsídios para discussão. In. ALVES, N. (org.) Formação de professores, pensar e fazer. São Paulo: Cortez, 1992, p. 53 71.

GINZBURG, C. Mitos, emblemas, sinais: morfologia e história. São Paulo: Companhia das Letras, 1991.

GOIÁS (Estado). Resolução CEPEC n 680 , de 09 de novembro de 2004. Fixa o Currículo Pleno do Curso de Graduação em Letras, modalidades Licenciatura Simples (Português, Espanhol, Francês, Inglês) e Bacharelado (Estudos Linguísticos, Estudos Literários), para os alunos ingressos a partir do ano letivo de 2005. Disponível em http://www.ufg.br/page.php?menu id=49\&pos=dir. Acesso em 02 de abril de 2009.

LAMPERT, E. Universidade, docência e globalização. Porto Alegre: Sulina, 1999.

MOITA LOPES, L. P. da. Oficina de lingística aplicada. Campinas, Mercado de Letras, 1996.

MORAES, R. Semeadores semeando suas sementes: a sala de aula na perspectiva do educar pela pesquisa. 2004. Mimeo.

PAVANELLO, R. M., A pesquisa na formação de professores de matemática para a escola básica. Educação Matemática em Revista, ano 10, n 15 , p. 8-13, 2003. 
ROZA, J. P. da. A pesquisa no processo de formação de professores: intenções e experiências docentes e discentes e as limitações deste exercício - um olhar sob duas realidades educacionais. Porto Alegre, 2005. Dissertação (Mestrado em Educação) Universidade Federal do Rio Grande do Sul.

RUZZA, R. C. P. de. Produção científica dos pesquisadores da EMBRAPA no estado de São Paulo: um estudo para subsidiar a geração de listas básicas de periódicos na área de agricultura. Campinas, 1990. Dissertação (Mestrado em Biblioteconomia) - Pontifícia Universidade Católica de Campinas.

SCHÖN, D. Educando o profissional reflexivo. Porto Alegre: Artmed, 2004.

SEVERINO, A. J. Pesquisa, pós-graduação e universidade. Revista da Faculdade Salesiana, Lorena, v. 24, n. 34, p. 60-68, 1996.

SUASSUNA, L. Pesquisa qualitativa em Educação e Linguagem: histórico e validação do paradigma indiciário. Revista perspectiva, Florianópolis, v. 26, n.1, 341-377, jan/jun, 2008.

TARDIF, M. Saberes profissionais dos professores e conhecimentos universitários: elementos para uma epistemologia da prática profissional dos professores e suas consequências em relação à formação para o magistério. Revista Brasileira de Educação (ANPED), $\mathrm{n}^{\mathrm{o}}$ 13, jan/fev/mar/abr, 2000.

VICKERY, B. C. The administration of research in institution. In: The advisory board on research of the library association, London. Objectives and Administration of Library research. London: The Library Association, 1972, p. 33-38. 